\title{
PREDICTION OF ULTIMATE FLEXURAL CAPACITY OF REINFORCED CONCRETE BEAMS STRENGTHENED WITH CFRP LAMINATE
}

\author{
M. H. Mansour and K. A. Mahmoud \\ Civil Eng. Dept., Faculty of Eng., Assiut University, Assiut, Egypt \\ E-mail:mhm_Soliman@yahoo.com
}

(Received August 3 ,2008 Accepted August 21, 2008)

\begin{abstract}
This study investigates the effect of externally bonded carbon fiber reinforced plastics (CFRP) laminates on the flexural capacity of reinforced concrete $(R C)$ beams used in the strengthening and repair of damaged structures. The main goal of this study is the development of analytical capabilities to predict the flexural behavior of $R C$ beams strengthened with CFRP. Reinforced concrete structures deteriorate over time due to environmental aging, fatigue, excessive loading, chemical attack, and other factors. Strengthening and rehabilitating these concrete structures by externally bonding carbon laminates is one of many economical engineering solutions. The final formulae of the required equations used to predict the flexural capacity, not only for rectangular sections but also for $T$ beams, had been derived. A comparison between the flexural capacities calculated using the derived equation and those obtained from experimental tests, from different references, is made to check the validity of the proposed procedure. A good agreement between the calculated and the tested values is obtained.
\end{abstract}

KEYWORDS: RC beams, T-beams, Retrofit, Repair, strengthening, CFRP, Advanced composite materials

\section{1-INTRODUCTION}

The board objective of this paper is to predict the ultimate moment capacity of RC beams strengthened externally with Carbon Fiber Reinforced Plastics (CFRP). Strengthening of RC structures can be performed by using steel or CFRP depending on the specific requirements of additional bending or shear reinforcement. It is also possible to combine the two materials. The CFRP sheets are used as externally strengthening material for many reasons. Among these reasons are the high tensile strength and stiffness of CFRP, the applying of the CFRP sheets is very easy, complex shapes and geometries can be done and labor costs are considerably lower for CFRP than for externally bonded steel stirrups. With growing needs for strengthening and rehabilitation of concrete structures, the external bonding of FRP laminates to reinforced concrete structures has attracted significant research in the two past decades. FRP composites are used in the repair and strengthening of columns, beams, slabs, walls, etc. The use of external CFRP reinforcement may be classified as flexural strengthening, improving the ductility of compression members, and shear strengthening [1]. 
The contribution of externally bonded CFRP laminates in shear capacity of RC beams is investigated by [1]. It is noticed that the beam with CFRP strips and the beam with CFRP fabrics have completely different failure mechanism where the failure of the strips is resulted from the concrete delimitation underneath the epoxy; while the failure of the fabrics is due to the fiber rapture. Consequently the CFRP strips increase more shear capacity than those of the CFRP fabrics [1]. A comparison of the development of shear carrying mechanisms in concrete beams reinforced with either steel or FRP reinforced had been done by [2]. To assist the increasing use of FRP composites in in situ repair techniques for RC structures, three dimensional non-linear elastic finite element analysis models of concrete beam strengthened with FRP composites have been developed by [3]. The stresses and strains that occur at the interface between the composite overlay and the concrete substrate have been studied [3].

The application of CFRP laminates as external reinforcement for flexural strengthening of RC beams with different steel ratios has been studied by [4]. The externally bonded CFRP sheets are used to strengthen a simple span reinforced concrete solid slab bridge to remove the load posting [5]. An analytical study on the flexural behavior of RC beams with rectangular section strengthened with externally bonded CFRP laminates is presented by [6].

It is noticed that many researches had used the CFRP widely to strengthen the RC beams with rectangular cross section; however few of them had studied the contribution of CFRP laminates to strengthen the RC beams with $\mathrm{T}$ section, although the RC beams with $\mathrm{T}$ sections are widely used in the design of RC structures such as ribbed beams, bridges, etc. So, the main objective of this study is to develop a simple and direct procedure to evaluate the flexural capacity of RC beams, with different cross section, strengthened with CFRP and to predict their failure modes.

\section{2-STRUCTURAL ANALYSIS OF RC BEAMS STRENGTHENED WITH ADVANCED COMPOSITE MATERIALS}

The analysis and design of RC beams according to the ultimate strength limit state design method will be used in this study. A number of assumptions imposing certain restrictions for the analysis and design of $\mathrm{RC}$ beams are considered. The most important of these assumptions are:

1- Stresses and strains are related by the material properties of concrete, steel and CFRP.

2- The Stress-Strain relationship is linear over the height of the cross section.

3- Resultant forces on the cross section must be balanced with the applied loads for static equilibrium.

4- The ultimate limit state assumes that at least one of the materials attains its maximum allowable strain.

5- Perfect bond is assumed between CFRP and concrete.

The above assumptions are valid irrespective how the member is loaded and how the shape of the cross section is elastically changed [6]. 


\section{2-1 Material properties:}

The stress strain curves for concrete and steel used in this study are shown in Fig.(1). Fig.(1-a) shows the typical stress strain curves for compressive concrete behavior which represented by a parabolic relationship up to a certain level, $\varepsilon=0.002$, then the strain increases while the stress remains constant. When the strains reach a maximum value, $\varepsilon_{c u}=0.003$, the concrete fails in compression. The ultimate strain of $\varepsilon_{c u}=0.003$ is a typical value for all grades of concrete. The ultimate strength $f_{\text {cu }}$ is given by the following expression:

$$
\frac{0.67 f_{c u}}{\gamma_{c}}= \begin{cases}0.45 f_{c u} & \text { for } \gamma_{c}=1.5 \text { (design) } \\ 0.67 f_{c u} & \text { for } \gamma_{c}=1.0 \text { (testing) }\end{cases}
$$

where, a factor of 0.67 is normally used for compensating for difference between the flexural strength and the cube crushing strength of concrete [6], and $\gamma_{c}=1.5$ is a safety factor for the strength of concrete when the designed member is cast in situ, or $\gamma_{c}=1.0$ when the member is cast in the laboratory for testing.

Fig.(1-b) shows the typical stress strain for steel reinforcement which is assumed to be identical in tension and compression. The behavior of steel reinforcement is linear in the elastic range up to the yield stress, $f_{y} / \gamma_{s}$, and then it becomes perfect plastic up to failure. The relationship between the steel stress $f_{s}$ and steel strain $\varepsilon_{s}$ can be written in the form:

$$
\varepsilon_{s}=\frac{f_{s} / \gamma_{s}}{E_{s}}
$$

where, $E_{s}$ is the modulus of elasticity of steel, and $\gamma_{s}=1.15$ is a factor of safety for the steel for design purpose, or $\gamma_{s}=1.0$ for testing. From equation (2), the yield strain of steel can be calculated from the following equation:

$$
\varepsilon_{y}=\frac{f_{y} / \gamma_{s}}{E_{s}}
$$

Fig.(1-c) shows a typical stress-strain curve for CFRP laminates in tension. The relationship between the stress $f_{f}$ and strain $\varepsilon_{f}$ is linear and the elastic. The stress strain relationship can be written in the form:

$$
f_{f}=E_{f} \varepsilon_{f}
$$

where $E_{f}$ is the modulus of elasticity of CFRP. 


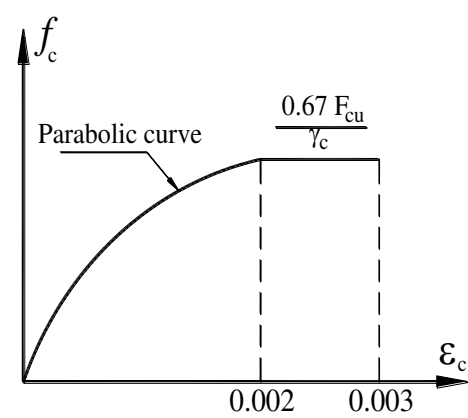

(a) Concrete

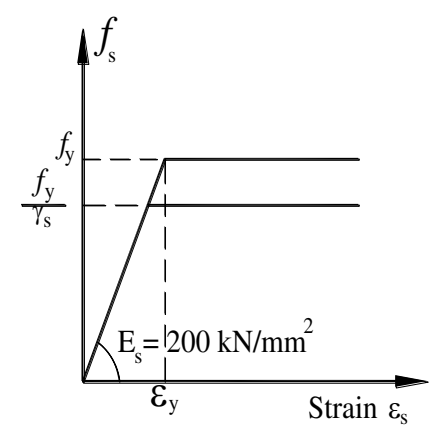

(b) Steel for tension and compression

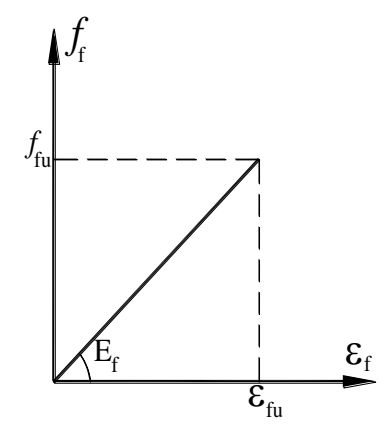

(c) CFRP in tension

Fig.(1): Typical stress-strain curves for concrete, steel and CFRP laminate

\section{2-2 Analysis of RC Sections Strengthened by CFRP Sheets:}

In analyzing the bending of RC beams, it is assumed that the concrete will crack at the ultimate tensile strain, and hence all the tension loads will be carried by the tensile steel reinforcement and the CFRP laminates. It is also assumed that the entire transverse section of a structural member remains in plane after bending and the strain distribution is linear within the section. Two cases of sections will be analyzed subjected to bending moment, $\mathrm{T}$ section and rectangular section.

\section{2-2-1 Analysis of T Beams Subjected to Bending Moment:}

The analysis of $\mathrm{T}$ beams subjected to bending moment is dependant on the position of the neutral axis. Fig. (2) Shows a T-section having a flange width B, web width $b$, and flange thickness $t_{\mathrm{s}}$. Assuming the neutral axis lies within the flange and from the strain diagram, the relationships between the neutral axis depth, $\mathrm{c}$, and the ultimate concrete strain, the steel strain and CFRP strain are given by:

$$
\begin{aligned}
& \varepsilon_{s}=\left(\frac{d-c}{c}\right) \varepsilon_{c u}=\left(\frac{1}{\eta}-1\right) \varepsilon_{c u} \\
& \varepsilon_{s}^{\prime}=\left(\frac{c-d^{\prime}}{c}\right) \varepsilon_{c u}=\left(1-\frac{\delta^{\prime}}{\eta}\right) \varepsilon_{c u} \\
& \varepsilon_{f}=\left(\frac{d_{f}-c}{c}\right) \varepsilon_{c u}=\left(\frac{\delta_{f}}{\eta}-1\right) \varepsilon_{c u}
\end{aligned}
$$

where,

$$
\eta=\frac{c}{d}, \quad \delta^{\prime}=\frac{d^{\prime}}{d}, \quad \delta_{f}=\frac{d_{f}}{d}
$$

From the equilibrium condition, the equilibrium equation can be written in the following form:

$$
\frac{0.67 f_{c u}}{\gamma_{c}} B \beta c+A_{s}^{\prime} f_{s}{ }^{\prime}=A_{s} f_{s}+A_{f} f_{f}
$$


Dividing equation (9) by $b d$ yields:

$$
\frac{0.67 f_{c u}}{\gamma_{c}}\left(\frac{B}{b}\right) \beta \eta+\rho^{\prime} f_{s}^{\prime}=\rho f_{s}+\rho_{f} f_{f}
$$

where,

$$
\rho=\frac{A_{s}}{b d}, \quad \rho^{\prime}=\frac{A_{s}^{\prime}}{b d}, \quad \rho_{f}=\frac{A_{f}}{b d}
$$

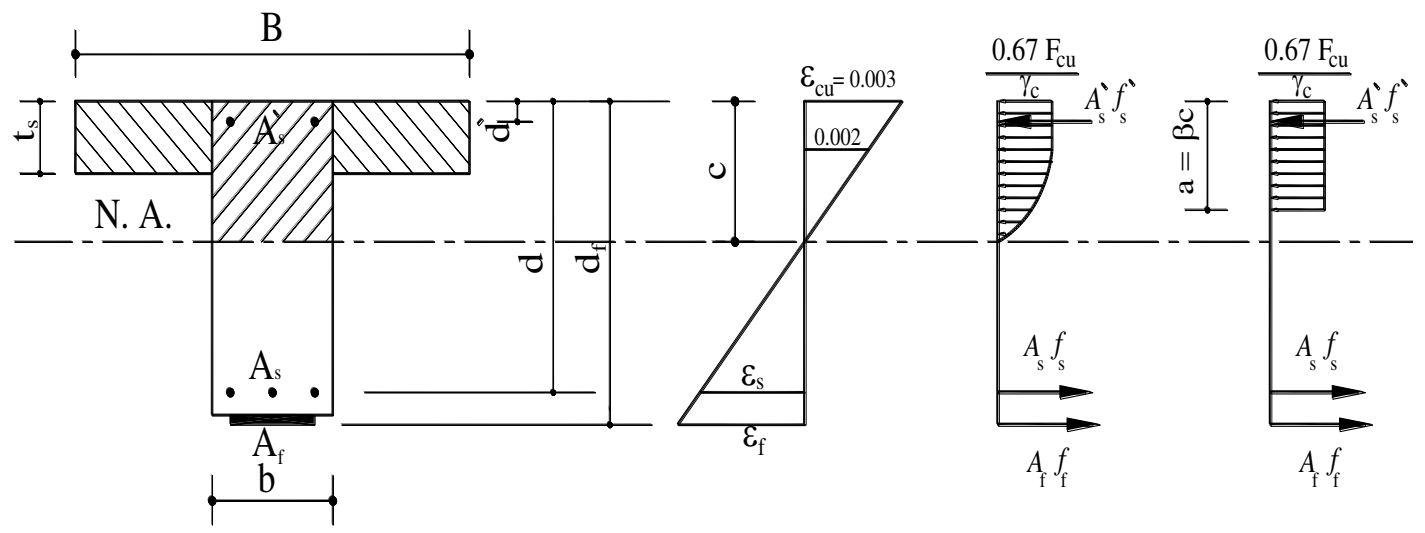

Fig. (2): Equivalent forces acting on T- beams strengthened with CFRP laminates.

Taking moments about the level of the laminate plate yields:

$$
M=\frac{0.67 f_{c u}}{\gamma_{c}} \beta B c\left(d_{f}-0.5 \beta c\right)+A_{s}^{\prime} f_{s}^{\prime}\left(d_{f}-d^{\prime}\right)-A_{s} f_{s}\left(d_{f}-d\right)
$$

Dividing equation (12) by $b d^{2}$ yields:

$$
\frac{M}{b d^{2}}=\frac{0.67 f_{c u}}{\gamma_{c}} \beta\left(\frac{B}{b}\right) \eta\left(\delta_{f}-0.5 \beta \eta\right)+\rho^{\prime} f_{s}^{\prime}\left(\delta_{f}-\delta^{\prime}\right)-\rho f_{s}\left(\delta_{f}-1\right)
$$

When $c$ is greater than $t_{s}$, the neutral axis lies outside the flange. For this position of the neutral axis the whole of the flange and a part of the web will be in compression. From Fig. (2), the equilibrium equation in this case can be written in the following form:

$$
\frac{0.67 f_{c u}}{\gamma_{c}} \beta \eta+\frac{0.67 f_{c u}}{\gamma_{c}} \alpha+\rho^{\prime} f_{s}^{\prime}=\rho f_{s}+\rho_{f} f_{f}
$$

where,

$$
\alpha=\left(\frac{\mathrm{t}_{\mathrm{s}}}{\mathrm{d}}\right)\left(\frac{\mathrm{B}}{\mathrm{b}}-1\right)
$$

Taking moments about the level of the laminate plate yields:

$$
\frac{M}{b d^{2}}=\frac{0.67 f_{c u}}{\gamma_{c}} \beta \eta\left(\delta_{f}-0.5 \beta \eta\right)+\frac{0.67 f_{c u}}{\gamma_{c}} \alpha\left(\delta_{f}-0.5 \frac{t_{s}}{d}\right)+\rho^{\prime} f_{s}^{\prime}\left(\delta_{f}-\delta^{\prime}\right)-\rho f_{s}\left(\delta_{f}-1\right)
$$




\section{2-2-2 Analysis of rectangular beams subjected to bending moment:}

The analysis of rectangular beams subjected to bending moment can be considered as a special case of the analysis of $\mathrm{T}$ beams when the position of the $\mathrm{N}$. A lies within the flange but with $\mathrm{B}=\mathrm{b}$. Fig. (3) shows the equivalent forces acting on a rectangular beam strengthened with CFRP laminates. From the equilibrium condition, the equilibrium equation in this case can be written in the following form:

$$
\frac{0.67 f_{c u}}{\gamma_{c}} \beta \eta+\rho^{\prime} f_{s}^{\prime}=\rho f_{s}+\rho_{f} f_{f}
$$

Taking moments about the level of the laminate plate yields:

$$
\frac{M}{b d^{2}}=\frac{0.67 f_{c u}}{\gamma_{c}} \beta \eta\left(\delta_{f}-0.5 \beta \eta\right)+\rho^{\prime} f_{s}^{\prime}\left(\delta_{f}-\delta^{\prime}\right)-\rho f_{s}\left(\delta_{f}-1\right)
$$

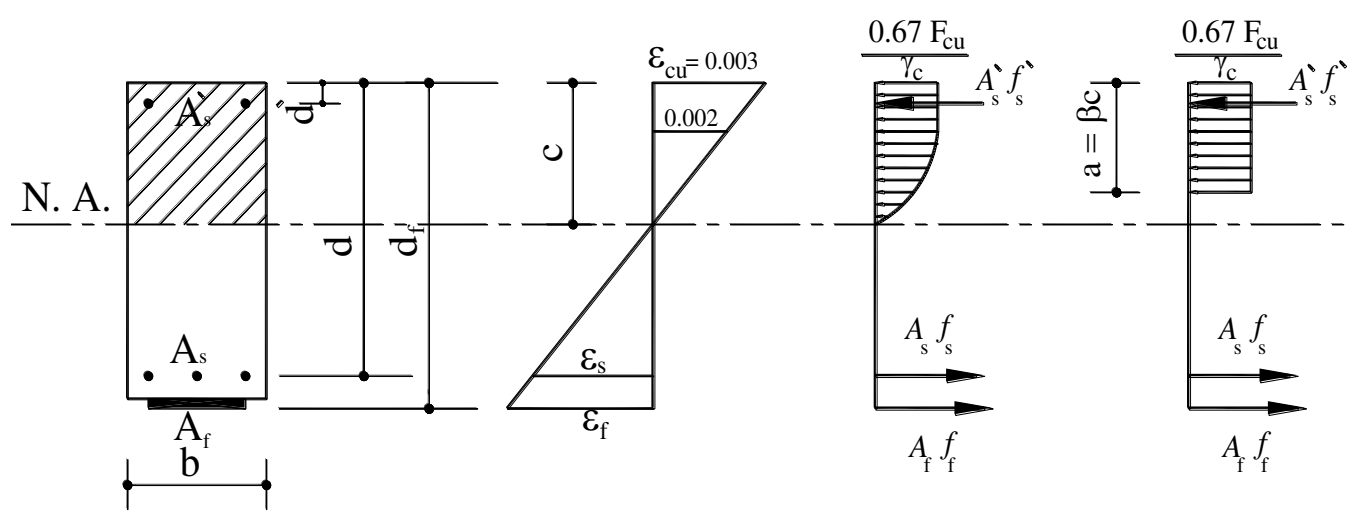

Fig. (3): Equivalent forces acting on rectangular beams strengthened with CFRP laminates.

\section{3- MODE OF FLEXURAL FAILURES:}

The use of CFRP laminates as external tensile reinforcement to repair or strengthen beams or slabs increase the strength (ultimate limit state) and the stiffness (serviceability limit state) of the structure. Unfortunately, the increase in strength and stiffness is sometimes realized at the expense of loss in ductility. Brittle failure is oftentimes caused by debonding or anchorage failure, which occurs in the majority of tests of beams strengthened for flexure [4]. The most common failure modes of RC beams strengthened with CFRP reinforcement are:

1. Compression failure: This type of failure has a brittle nature and occurs suddenly without previous warning when the concrete attains its ultimate compressive strain while the steel and CFRP strains are relatively low. The section failed in this mode is over reinforced section. The steel ratio of this section is higher than the balanced steel ratio.

2. Tension failure: This type of failure has a ductile nature and it provides ample warning against imminent failure. The section failed in this mode is lightly reinforced. When failure occurs, it will be initiated by yielding of the reinforcing 
steel on the tension side. This type of failure is favorable because it provides the maximum flexural capacity with a minimal reinforcement.

3. CFRP rupture: The rapture of CFRP laminate follows the yielding of reinforcing steel in tension before the concrete attains the ultimate compressive strain. This type of failure is less ductile failure.

It is obvious that the type of failure depends on the steel and CFRP ratio. To determine the failure mode, upper and lower limits of both reinforcing bars and CFRP areas have to be established to ensure the failure of the beam will be in a ductile fashion.

\section{3-1 Tension Failure:}

Figure (4) shows the strain distribution for the balanced steel section at collapse. At failure, the concrete strain at the extreme compression fiber $\varepsilon_{c}$ reaches the ultimate strain, $\sqcup \varepsilon_{c u}=0.003$, simultaneously with the bottom tensile steel strain, $-\varepsilon_{s}$ reaching yield strain, $-\varepsilon_{y}$. Meanwhile, the compression steel strain $\varepsilon_{s}^{\prime}>\varepsilon_{y}^{\prime}$ and the CFRP strain $\varepsilon_{f}<\varepsilon_{f u}$. The depth factor of the neutral axis $(\eta=\mathrm{c} / \mathrm{d})$ has a value and is given in equation (5) with $\varepsilon_{s}$ and can be replaced by $\varepsilon_{y}$ :

$$
\eta_{1}=\frac{\varepsilon_{c u}}{\varepsilon_{c u}+\varepsilon_{y}}
$$

The strain in the CFRP sheets will be:

$$
\varepsilon_{f}=\left(\frac{\delta_{f}}{\eta_{1}}-1\right) \varepsilon_{c u}
$$

In this case, the equation of the force equilibrium given by equations (10), (14) and (17) with $f_{s}$ replaced by $f_{y} / \gamma_{s}$ and $f_{s}^{\prime}$ by $f_{y}^{\prime} / \gamma_{s}$ become:

For $\mathrm{T}$ beams with the neutral axis lies inside the slab:

$$
\frac{0.67 f_{c u}}{\gamma_{c}}\left(\frac{B}{b}\right) \beta \eta+\rho^{\prime}\left(\frac{f_{y}^{\prime}}{\gamma_{s}}\right)=\rho\left(\frac{f_{y}}{\gamma_{s}}\right)+\rho_{f} f_{f}
$$

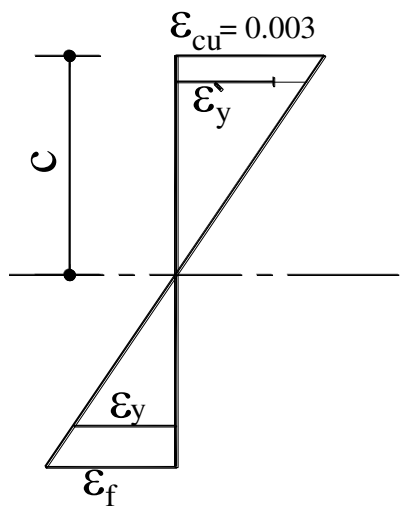

Fig. (4): Strain distribution for tension failure

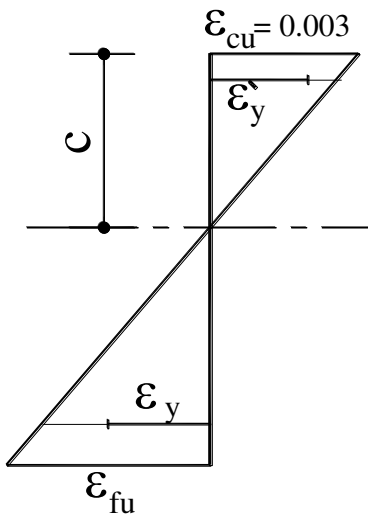

Fig. (5): Strain distribution for CFRP rapture 
From equation (21), a maximum CFRP cross sectional area $A_{f, \max }$ should be provided o prevent compression failure as follows:

$$
\rho_{f, \max }=\frac{\left(0.67 f_{c u} / \gamma_{c}\right)(B / b) \beta \eta_{1}+\rho^{\prime}\left(f_{y}^{\prime} / \gamma_{s}\right)-\rho\left(f_{y} / \gamma_{s}\right)}{E_{f} \varepsilon_{f}}
$$

Similarly $A_{f, \max }$ for $\mathrm{T}$ beams with the neutral axis lies without the slab written as follows:

$$
\rho_{f, \max }=\frac{\left(0.67 f_{c u} / \gamma_{c}\right) \beta \eta_{1}+\left(0.67 f_{c u} / \gamma_{c}\right) \alpha+\rho^{\prime}\left(f_{y}^{\prime} / \gamma_{s}\right)-\rho\left(f_{y} / \gamma_{s}\right)}{E_{f} \varepsilon_{f}}
$$

And for rectangular beams, $A_{f, \max }$ can be determined from the following equation:

$$
\rho_{f, \max }=\frac{\left(0.67 f_{c u} / \gamma_{c}\right) \beta \eta_{1}+\rho^{\prime}\left(f_{y}^{\prime} / \gamma_{s}\right)-\rho\left(f_{y} / \gamma_{s}\right)}{E_{f} \varepsilon_{f}}
$$

\section{3-2 CFRP Rapture:}

Figure (5) shows the strain distribution at collapse. At failure, the concrete strain at the extreme compression fiber $\varepsilon_{c}$ reaches the ultimate strain, $\varepsilon_{c u}=0.003$, simultaneously with the bottom CFRP strain, $\varepsilon_{f}$ reaching ultimate strain, $\varepsilon_{f u}$. Meanwhile, the compression steel strain $\varepsilon_{s}^{\prime}>\varepsilon_{y}^{\prime}$ and tension steel strain $\varepsilon_{s}>\varepsilon_{y}$. The depth factor of the neutral axis $(\eta=\mathrm{c} / \mathrm{d})$ has a value and is given in equation (7) with $\varepsilon_{f}$ and can be replaced by $\varepsilon_{f u}$ :

$$
\eta_{2}=\frac{\varepsilon_{c u}}{\varepsilon_{c u}+\varepsilon_{f u}} \delta_{f}
$$

In this case, the equation of the force equilibrium given by equations (10), (14) and (17) with $f_{s}$ replaced by $f_{y} / \gamma_{s}, f_{s}{ }^{\prime}$ by $f_{y}^{\prime} / \gamma_{s}$ and $f_{f}$ by $E_{f} \varepsilon_{f u}$ become:

For $\mathrm{T}$ beams with the neutral axis lies inside the slab:

$$
\frac{0.67 f_{c u}}{\gamma_{c}}\left(\frac{B}{b}\right) \beta \eta_{2}+\rho^{\prime}\left(\frac{f_{y}^{\prime}}{\gamma_{s}}\right)=\rho\left(\frac{f_{y}}{\gamma_{s}}\right)+\rho_{f} E_{f} \varepsilon_{f u}
$$

From the above equation, a minimum CFRP cross sectional area $A_{f, \text { min }}$ should be provided to prevent CFRP rapture before the concrete attains the ultimate compressive strain. The CFRP area $A_{f, \min }$ can be determined as follows:

$$
\rho_{f, \text { min }}=\frac{\left(0.67 f_{c u} / \gamma_{c}\right)(B / b) \beta \eta_{2}+\rho^{\prime}\left(f_{y}^{\prime} / \gamma_{s}\right)-\rho\left(f_{y} / \gamma_{s}\right)}{E_{f} \varepsilon_{f u}}
$$

Similarly $A_{f, \min }$ for T beams with the neutral axis lies without the slab can be written as follows: 


$$
\rho_{f, \min }=\frac{\left(0.67 f_{c u} / \gamma_{c}\right) \beta \eta_{2}+\left(0.67 f_{c u} / \gamma_{c}\right) \alpha+\rho^{\prime}\left(f_{y}^{\prime} / \gamma_{s}\right)-\rho\left(f_{y} / \gamma_{s}\right)}{E_{f} \varepsilon_{f u}}
$$

And for rectangular beams, $A_{f, \min }$ can be determined from the following equation:

$$
\rho_{f, \min }=\frac{\left(0.67 f_{c u} / \gamma_{c}\right) \beta \eta_{2}+\rho^{\prime}\left(f_{y}^{\prime} / \gamma_{s}\right)-\rho\left(f_{y} / \gamma_{s}\right)}{E_{f} \varepsilon_{f u}}
$$

\section{4- EVALUATION OF ULTIMATE FLEXURAL CAPACITY:}

In the previous section, equations for calculating the minimum and maximum areas of CFRP sheets are derived in closed form for different section shapes. To determine the ultimate flexural capacity (M) of RC section reinforced by tension steel reinforcement, $A_{s}$, compression steel reinforcement $A_{s}^{\prime}$, and strengthened with CFRP sheets, $A_{f}$, the values of $f_{s}$ will be replaced by $f_{y} / \gamma_{s}$ and $f_{s}^{\prime}$ by $f_{y}^{\prime} / \gamma_{s}$ in the force equilibrium equations.

\section{The Ultimate flexural capacity for $T$ section with neutral axis lies within the flange:}

Dividing by $\frac{0.67 f_{c u} / \gamma_{c}}{b d}$, equation (21) becomes:

$$
\left(\frac{\mathrm{B}}{\mathrm{b}}\right) \beta \eta+\phi^{\prime}=\phi+\phi_{f}\left(\frac{\delta_{f}}{\eta}-1\right)
$$

From equation (30) the value of $\eta$ can be written in the form:

$$
\eta=-\frac{\phi^{\prime}-\phi+\phi_{f}}{2 \beta(B / b)}+\frac{\sqrt{\left(\phi^{\prime}-\phi+\phi_{f}\right)^{2}+4 \beta(B / b) \delta_{f} \phi_{f}}}{2 \beta(B / b)}
$$

Taking moments about the level of the laminate plate yields:

$$
m=\beta(B / b) \eta\left(\delta_{f}-0.5 \beta \eta\right)+\phi^{\prime}\left(\delta_{f}-\delta^{\prime}\right)-\phi\left(\delta_{f}-1\right)
$$

where,

$$
\begin{array}{ll}
\phi & =\frac{f_{y} / \gamma_{s}}{0.67 f_{c u} / \gamma_{c}} \rho, \\
\phi_{f} & =\frac{E_{f} \varepsilon_{c u}}{0.67 f_{c u} / \gamma_{c}} \rho_{f} \quad, \quad m=\frac{M}{0.67 f_{c u} / \gamma_{c} b d^{2}}
\end{array}
$$

Equations (30) and (32) are the basis set of equations for analyzing the flexural behavior of RC beams strengthened with externally bonded CFRP laminates. Hence, a simple and direct computation procedure for design has been developed for calculating the CFRP cross sectional area, or evaluating the ultimate flexural capacity to ensure ductile behavior of tension failure or RC beams strengthened with CFRP laminates. 
Similar equations for $\mathrm{T}$ beams with neutral axis lies without the slab can be obtained as follows:

$$
\begin{aligned}
& \beta \eta+\alpha+\phi^{\prime}=\phi+\phi_{f}\left(\frac{\delta_{f}}{\eta}-1\right) \\
& \eta=-\frac{\alpha+\phi^{\prime}-\phi+\phi_{f}}{2 \beta}+\frac{\sqrt{\left(\alpha+\phi^{\prime}-\phi+\phi_{f}\right)^{2}+4 \beta \delta_{f} \phi_{f}}}{2 \beta} \\
& m=\beta \eta\left(\delta_{f}-0.5 \beta \eta\right)+\alpha\left(\delta_{f}-0.5 t_{s} / d\right)+\phi^{\prime}\left(\delta_{f}-\delta^{\prime}\right)-\phi\left(\delta_{f}-1\right)
\end{aligned}
$$

For rectangular cross section, the equations are:

$$
\begin{aligned}
& \beta \eta+\phi^{\prime}=\phi+\phi_{f}\left(\frac{\delta_{f}}{\eta}-1\right) \\
& \eta=-\frac{\phi^{\prime}-\phi+\phi_{f}}{2 \beta}+\frac{\sqrt{\left(\phi^{\prime}-\phi+\phi_{f}\right)^{2}+4 \beta \delta_{f} \phi_{f}}}{2 \beta} \\
& m=\beta \eta\left(\delta_{f}-0.5 \beta \eta\right)+\phi^{\prime}\left(\delta_{f}-\delta^{\prime}\right)-\phi\left(\delta_{f}-1\right)
\end{aligned}
$$

\section{5- DETERMINATION OF CFRP AREA:}

For a known value of bending moment $(\mathrm{M})$ acting on a $\mathrm{RC}$ section reinforced by tension steel reinforcement, $A_{s}$ and compression steel reinforcement $A_{s}^{\prime}$, the determination of CFRP area, $A_{f}$, can be obtained as follows:

1- Calculate the following values, $\phi, \phi^{\prime}, m, \eta_{1}, \eta_{2}$

2- Find the value of neutral axis depth, $\eta$, and check $\eta_{2}<\eta<\eta_{1}$ (From the moment equation)

3- Calculate the CFRP area from the force equilibrium equation

For $\mathrm{T}$ beam with the neutral axis lies within the flange, the values of $\eta$ and $A_{f}$ can be determined from equations (32), (30) respectively as follows:

$$
\begin{aligned}
& \eta=\frac{\delta_{f}}{\beta}-\sqrt{\left(\frac{\delta_{f}}{\beta}\right)^{2}-\frac{2(b / B)\left[m+\phi\left(\delta_{f}-1\right)-\phi^{\prime}\left(\delta_{f}-\delta^{\prime}\right)\right]}{\beta^{2}}} \\
& \phi_{f}=\frac{(\mathrm{B} / \mathrm{b}) \beta \eta+\phi^{\prime}-\phi}{\delta_{f} / \eta-1}, \rho_{f}=\frac{0.67 f_{c u} / \gamma_{c}}{E_{f} \varepsilon_{c u}} \phi_{f}=A_{f} b d
\end{aligned}
$$

For $\mathrm{T}$ beam with the neutral axis lies without the flange, the values of $\eta$ and $A_{f}$ can be determined from equations (36), (34) respectively as follows: 


$$
\begin{gathered}
\eta=\frac{\delta_{f}}{\beta}-\sqrt{\left(\frac{\delta_{f}}{\beta}\right)^{2}-\frac{2\left[m+\phi\left(\delta_{f}-1\right)-\alpha\left(\delta_{f}-0.5 t_{s} / d\right)-\phi^{\prime}\left(\delta_{f}-\delta^{\prime}\right)\right]}{\beta^{2}}} \\
\phi_{f}=\frac{\beta \eta+\alpha+\phi^{\prime}-\phi}{\delta_{f} / \eta-1}, \quad \rho_{f}=\frac{0.67 f_{c u} / \gamma_{c}}{E_{f} \varepsilon_{c u}} \phi_{f}=A_{f} b d
\end{gathered}
$$

For rectangular cross section, the values of $\eta$ and $A_{f}$ can be determined from equations (39), (37) respectively as follows:

$$
\begin{aligned}
& \eta=\frac{\delta_{f}}{\beta}-\sqrt{\left(\frac{\delta_{f}}{\beta}\right)^{2}-\frac{2\left[m+\phi\left(\delta_{f}-1\right)-\phi^{\prime}\left(\delta_{f}-\delta^{\prime}\right)\right]}{\beta^{2}}} \\
& \phi_{f}=\frac{\beta \eta+\phi^{\prime}-\phi}{\delta_{f} / \eta-1}, \quad \rho_{f}=\frac{0.67 f_{c u} / \gamma_{c}}{E_{f} \varepsilon_{c u}} \phi_{f}=A_{f} b d
\end{aligned}
$$

\section{6- VERIFICATION OF THE DERIVED EQUATIONS FOR THE FLEXURAL ANALYSIS}

To check the accuracy of the derived equations for section analysis described in this study, a comparison between the predicted ultimate flexural strength using the analytical method described in this paper and the ultimate flexural strength obtained experimentally by different researchers is made. The value of $\beta$ is assumed to be 0.8 and the value of $\varepsilon_{c u}$ is assumed to be 0.003 for all grades of concrete. The factor of safety for both steel and concrete is assumed to equal 1.0. Several researches had tested $\mathrm{RC}$ beams up to failure.

In this study, the two simply supported RC beams, J-4 tested by Burns and Siess [7] and A-1 tested by Bresler [8], are chosen to investigate the analytical procedure described in this paper. Also, two rectangular slab beams, in full-scale, used by Mayo et al. [5] are analyzed and compared with the experimental data. These beams are tested in laboratory to failure to mimic an existing bridge, G270. The first beam was tested to failure without strengthening and the second one was strengthened using one play of CFRP (Mbrace ${ }^{\mathrm{TM}}$ CF-130) $304.8 \mathrm{~mm}$ wide, $0.165 \mathrm{~mm}$ thickness, tensile modulus of $235 \mathrm{Gpa}$ and a tensile ultimate strength of $3820 \mathrm{Mpa}$. Table (1) shows the material properties and the results of comparison.

To check the validity of the derived equations of T-beams, the results of Tbeams included in the paper of Mattock et al. [9] are used in this study. These beams were used to validate the derivation of the equivalent rectangular concrete stress distribution in ultimate strength design. Table (2) shows the material properties of the tested beams and the comparison of the test results with the predicted values.

Finally, to check the validity of the derived equations of RC beams strengthened with CFRP laminates, a comparison between the predicted ultimate flexural capacity and the ultimate flexural capacity obtained experimentally for the second beam tested by different researchers is made. Table (3) shows the material 
properties of the tested beams and the comparison of the test results with the predicted values.

Table (1): comparison between experimental and predicted results for rectangular beams

\begin{tabular}{|c|c|c|c|c|c|c|c|c|c|c|c|c|c|}
\hline Ref. & Beam & $\begin{array}{c}\mathrm{b} \\
m m\end{array}$ & $\begin{array}{c}\mathrm{d} \\
m m\end{array}$ & $\begin{array}{c}\mathrm{d}_{\mathrm{f}} \\
m m\end{array}$ & $\begin{array}{c}\mathrm{d}^{\prime} \\
m m\end{array}$ & $\begin{array}{c}\mathrm{A}_{\mathrm{s}} \\
m^{2}\end{array}$ & $\begin{array}{c}\mathrm{A}^{\prime}{ }_{\mathrm{s}} \\
m^{2}\end{array}$ & $\begin{array}{c}\mathrm{F}_{\mathrm{cu}} \\
M P a\end{array}$ & $\begin{array}{c}f_{\mathrm{y}} \\
M P a\end{array}$ & $\begin{array}{c}f^{\prime}{ }_{\mathrm{y}} \\
M P a\end{array}$ & $\begin{array}{c}\mathrm{M}_{\mathrm{t}} \\
k N . m\end{array}$ & $\begin{array}{c}\mathrm{M}_{\mathrm{c}} \\
k N . m\end{array}$ & $\mathrm{M}_{\mathrm{t}} / \mathrm{M}_{\mathrm{c}}$ \\
\hline$[7]$ & $\mathrm{J}-4$ & 203 & 457 & 508 & 0 & 9.20 & 0 & 42.5 & 315.6 & 0 & 141 & 126 & 1.12 \\
\hline$[8]$ & $\mathrm{A}-1$ & 300 & 430 & 553 & 40 & 24.62 & 2.26 & 30.0 & 566.0 & 352.3 & 412 & 453 & 0.91 \\
\hline$[5]$ & TEST & 381 & 470 & 500 & 0 & 968 & 0 & 39.8 & 520 & 0 & 214 & 224 & 0.96 \\
\hline
\end{tabular}

where, $\mathrm{M}_{\mathrm{t}}$ is the ultimate flexural capacity obtained experimentally and $M_{c}$ is the predicted ultimate flexural capacity

Table (2): comparison between experimental and predicted results for $\mathrm{T}$ beams

\begin{tabular}{|c|c|c|c|c|c|c|c|c|c|c|c|c|c|}
\hline \multirow{2}{*}{ Ref. } & Beam & $\begin{array}{c}\mathrm{b} \\
m m\end{array}$ & $\begin{array}{c}\mathrm{d} \\
m m\end{array}$ & $\begin{array}{c}\mathrm{d}_{\mathrm{f}} \\
m m\end{array}$ & $\begin{array}{c}\mathrm{B} \\
m m\end{array}$ & $\begin{array}{c}\mathrm{t}_{\mathrm{s}} \\
m m\end{array}$ & $\begin{array}{c}\mathrm{A}_{\mathrm{s}} \\
m m^{2}\end{array}$ & $\begin{array}{c}\mathrm{F}_{\mathrm{cu}} \\
M P a\end{array}$ & $\begin{array}{c}f_{\mathrm{y}} \\
M P a\end{array}$ & $\begin{array}{c}\mathrm{M}_{\mathrm{t}} \\
k N . m\end{array}$ & $\begin{array}{c}\mathrm{c} \\
m m\end{array}$ & $\begin{array}{c}\mathrm{M}_{\mathrm{c}} \\
k N . m\end{array}$ & $\mathrm{M}_{\mathrm{t}} / \mathrm{M}_{\mathrm{c}}$ \\
\hline \multirow{6}{*}[9]{} & $2^{*}$ & 203 & 254 & 305 & 813 & 83 & 2167 & 16.12 & 371 & 181.93 & 147 & 166.43 & 1.09 \\
\cline { 2 - 15 } & $3^{*}$ & 203 & 254 & 305 & 610 & 83 & 1445 & 15.17 & 363 & 125.09 & 110 & 111.03 & 1.14 \\
\cline { 2 - 14 } & $4^{*}$ & 203 & 254 & 305 & 406 & 83 & 1135 & 11.46 & 264 & 71.19 & 137 & 61.44 & 1.16 \\
\cline { 2 - 13 } & 6 & 203 & 254 & 305 & 610 & 83 & 1419 & 13.88 & 264 & 87.35 & 83 & 82.78 & 1.06 \\
\cline { 2 - 13 } & $7^{*}$ & 203 & 254 & 305 & 406 & 83 & 1135 & 12.50 & 264 & 65.31 & 131 & 65.85 & 0.99 \\
\cline { 2 - 12 } & 8 & 203 & 254 & 305 & 610 & 83 & 1419 & 15.08 & 281 & 88.71 & 81 & 88.38 & 1.00 \\
\hline & 9 & 203 & 254 & 305 & 813 & 83 & 1987 & 14.15 & 264 & 113.57 & 83 & 115.2 & 0.99 \\
\hline
\end{tabular}

*Denotes T-beams where $\mathrm{c}>\mathrm{t}_{\mathrm{s}}$ at nominal flexure strength.

Table (3): Comparison between experimental and predicted results for strengthened RC beams

\begin{tabular}{|c|c|c|c|c|c|c|c|c|c|c|c|c|c|c|c|}
\hline Ref. & Beam & $\begin{array}{c}\mathrm{b} \\
m m\end{array}$ & $\underset{m m}{\mathrm{~d}}$ & $\begin{array}{r}\mathrm{d}_{\mathrm{f}} \\
m m\end{array}$ & $\begin{array}{c}\mathrm{d}^{\prime} \\
m m\end{array}$ & $\begin{array}{c}\mathrm{A}_{\mathrm{s}} \\
m^{2}\end{array}$ & $\begin{array}{c}\mathrm{A}^{\prime}{ }_{s} \\
m m^{2}\end{array}$ & $\begin{array}{c}\mathrm{A}_{\mathrm{f}} \\
\mathrm{mm}^{2}\end{array}$ & $\begin{array}{c}f_{\mathrm{f}} \\
M P a\end{array}$ & $\begin{array}{c}E_{\mathrm{f}} \\
G P a\end{array}$ & $\begin{array}{l}\mathrm{F}_{\mathrm{cu}} \\
\mathrm{MPa}\end{array}$ & $\begin{array}{c}f_{\mathrm{y}} \\
M P a\end{array}$ & $\begin{array}{c}\mathrm{M}_{\mathrm{t}} \\
k N . m\end{array}$ & $\begin{array}{c}\mathrm{M}_{\mathrm{c}} \\
k N . m\end{array}$ & $\mathrm{M}_{\mathrm{t}} / \mathrm{M}_{\mathrm{c}}$ \\
\hline [5] & TEST & 381 & 470 & 500 & 0 & 968 & 0 & 50.29 & 3820 & 235 & 39.8 & 520 & 275 & 302 & 0.91 \\
\hline \multirow{2}{*}{ [10] } & A & \multirow{2}{*}{205} & \multirow{2}{*}{400} & \multirow{2}{*}{455} & \multirow{2}{*}{55} & 1520 & \multirow{2}{*}{253} & \multirow{2}{*}{912} & \multirow{2}{*}{400} & \multirow{2}{*}{37.2} & \multirow{2}{*}{35} & \multirow{2}{*}{456} & 320 & 283 & 1.13 \\
\hline & B & & & & & 1013 & & & & & & & 255 & 243 & 1.05 \\
\hline$[2]^{*}$ & GB45R & 150 & 223 & 250 & 0 & 429.4 & 0 & 0 & 750 & 45 & 54 & 0 & 52.5 & 62.26 & 0.85 \\
\hline [4] & $4 \mathrm{~b}$ & 125 & 413 & 457 & 0 & 253 & 0 & 122 & 2400 & 155 & 53.4 & 42.7 & 151 & 149.25 & 1.01 \\
\hline
\end{tabular}

* Beam GB45R is reinforced in flexure with GFRP bars as tensile reinforcement and failed in flexure.

\section{7- CONCLUSION}

In this study, the derivation of the necessary equations required to predict the ultimate flexural capacity for RC beams strengthened with CFRP laminates has been achieved. The paper includes derived equations not only for rectangular section but also for Tbeam section. For T-beams, the derived equations depend on whether the neutral axis 
of the beam lies within or without the flange. Equations for both cases are derived in closed form. Based on this study, several findings are presented as follows:

1- A maximal and minimal value of CFRP area which enables the beam to fail under tension or CFRP rapture is determined in a closed form for all the beam cases.

2- A simple and direct procedure has been developed to predict the ultimate flexural load capacity of a concrete beam strengthened with CFRP laminates.

3- A comparison between the predicted flexural capacity and the experimental results obtained by different researches has been made. A good agreement between the analytical results and the experimental results is obtained. The maximum difference between the predicted values and the experimental values does not exceed $15 \%$.

4- From the comparison, the derived equations are more accurate for rectangular sections than T-beams especially when the neutral axis lies without the flange.

5- In all cases where the depth of the neutral axis exceeds the depth of the flange at nominal flexural strength, the ratio $M_{t} / M_{c}$ is unity or greater.

\section{8- REFRENCES}

1. Zhang, Z. and Hsu, C. T.: "Shear strengthening of RC Beams Using Carbon Fiber Reinforced Polymer Strips", $15^{\text {th }}$ ASCE Engineering Mechanics Conference, Columbia University, New York, June 2002.

2. Guadagnini, M. Pilakoutas, K. and Waldron, P.: "Shear Performance of FRP Reinforced Concrete Beams", Journal of Reinforced Plastics and Composites, V. 22, No. 15, pp. 1389-1407, 2003.

3. Huang, D. and Lyons, J.: "Numerical Stress Analysis of the Bond between Reinforced Concrete T-Beam and FRP Sheets", Journal of Reinforced Plastics and Composites, V. 26, No. 12, pp. 1225-1237, 2007.

4. Duthinh, D. and Starnes, M.: "Strengthening of Reinforced Concrete Beams with Carbon FRP", Composites in Constructions, Figueiras et al (eds), Swets \& Zeitlinger, Lisse, pp. 493-498, 2001.

5. Mayo, R., Nanni, A., Gold, W. and Barker, M.: "Strengthening of Bridge G270 with Externally -Bonded CFRP Reinforcement", SP-188, American Concrete Institute, Proc., $4^{\text {th }}$ International Symposium on FRP for Reinforcement of Concrete Structures, (FRPRCS4), Baltimore, MD, pp. 429-440, Nov. 1999.

6. NG, S. C. and Lee, S.: "A Study of Flexural Behavior of Reinforced Concrete Beam Strengthened with Carbon Fiber-Reinforced Plastic (CFRP)", Journal of Reinforced Plastics and Composites, V. 21, No. 10, pp. 919-938, 2002.

7. Burns, N. H. and Siess, C. P.: "Load-deformation characteristics of beam-column connections in reinforced concrete", Civil Engineering Studies, SRS no. 234, University of Illinois at Urbana. IL, 1962.

8. Bresler, B. and Scordelis, A. C.: "Shear Strength of Reinforced concrete beams", ACI Journal, V. 60, No. 1, pp. 51-72, 1963.

9. Mattock, A. H., Kriz, L. B., And Hognestad, E.: " Rectangular Concrete Stress Distribution in Ultimate Strength Design", ACI Journal, V. 32, No. 8, pp. 875-928, 1961. 
10. Saadatmanesh, H. and Ehsani, M. R.: "RC beams strengthened with GFRP plates.

I: Experimental Study", J. of Struct. Eng., ASCE, 117 (11), pp. 3417-3433, 1991.

\section{التنبؤ بالسعة القصوى لعزم الانحناء للكمرات الخرسانية المسلحة المقواة باستخدام رقائق الكريون CFRP}

في هذه الدراسة نم انتقاق المعادلات الضرورية اللازمة لحساب السعة القصوى لعزم الانحناء للكمرات

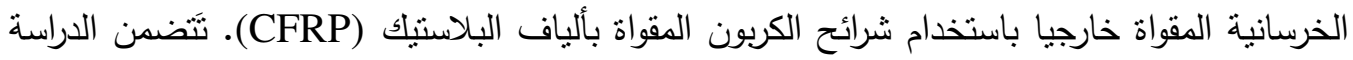

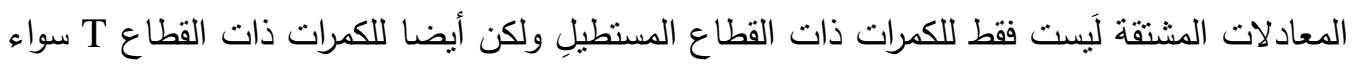
كان محور الخمول يقع داخل البلاطة أو خارجها. وقد تم اشتقاق المعادلات للحالات المختلفة في صورة نهائية محددة (closed form) مما يساعد في حساب سعة العزم القصوى للقطاع بصورة سهلة



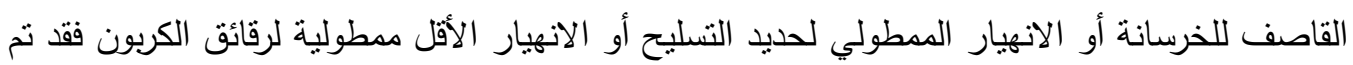

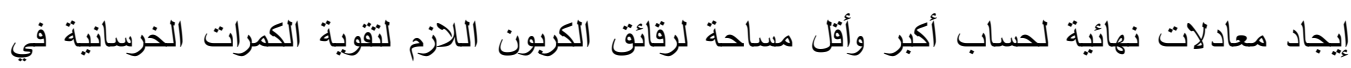

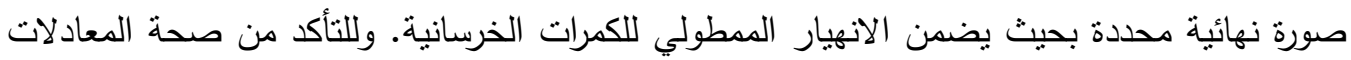

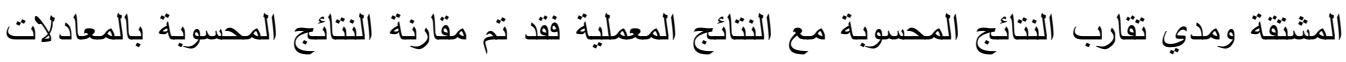
المعطاة في هذا البحث مع النتائج المعلية التي تم الحصول عليها معطليا عن طريق العديد من

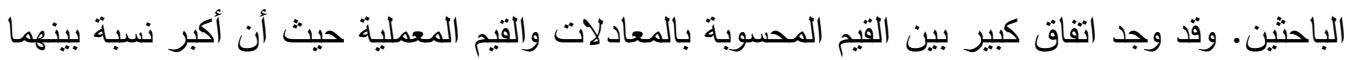
لا يتجاوز 15\%. كما تنين أن المعادلات المشتقة تكون أكثر تقاربا للكمرات ذات القطاع المستطيل عنها للكمرات ذات القطاع T كما لوحظ أنه في كل الحالات التي يكون محور الخمول واقعا خارج البلاطة فإن قيمة العزم الذي نحصل عليه من المعمل يكون أكبر من القيمة المحسوبة بالمعادلات. 